\title{
Effect of Grape Pomace Powder Addition on TBARS and Color of Cooked Pork Sausages during Storage
}

\author{
Kyeong Seon Ryu ${ }^{1, \#}$, Kwan Seob Shim ${ }^{2, \#}$, and Daekeun Shin ${ }^{1,3, *}$ \\ ${ }^{1}$ Department of Animal Science, Chonbuk National University, Jeonju 561-756, Korea \\ ${ }^{2}$ Department of Animal Biotechnology, Chonbuk National University, Jeonju 561-756, Korea \\ ${ }^{3}$ Department of Food and Nutrition, Hallym University, Chuncheon 200-702, Korea
}

\begin{abstract}
To determine the effects of grape skin and seed pomace (GSP) additions on the lipid oxidation susceptibility and the color change of cooked pork sausages, the chemical characteristics of GSP itself and the addition for two different levels of GSP ( 0.5 and $1.0 \%$ GSP, respectively) to sausages were examined. Both the redness and blueness of the GSP were significantly reduced as the $\mathrm{pH}$ level was increased from 5 to 7 , but a reverse result was determined in the color tint and yellowness $(p<0.05)$. The GSP polyphenol and flavonoid contents were influenced by the percentages of methanol solvents, and more flavonoids were established when $100 \%$ of methanol was applied as a solvent to the GSP. But, similar results were not observed in the polyphenol of GSP. In cooked pork sausages, significant decreases in the lightness and redness were found in both the $0.5 \%$ and $1.0 \%$ of GSP sausages during the storage period $(p<0.05)$. However, an incompatible effect was observed in terms of yellowness, which increased as compared to the control sausage after 6 days of storage. The $0.5 \%$ addition of GSP decreased the levels of TBARS $(p<0.05)$, but the ability of GSP to minimize lipid oxidation was not dose dependent. Therefore, the results indicated that the GSP is an efficient suppressor of lipid oxidation and has latent effects as a natural antioxidant when $0.5 \%$ of GSP is added to the cooked pork sausages.
\end{abstract}

Key words: grape skin and seed pomace, pork sausage, polyphenol, flavonoid, lipid oxidation

\section{Introduction}

Increasing shelf life is one of the major strategies towards improving the economic value of pork and pork products. Efforts are being made to extend the shelf life of pork and its products by reducing the number of free radicals formed as a result of the interaction between unsaturated fatty acids and initiators (Angelo, 1996). Synthetic phenolic antioxidants, including butylated hydroxyanisole (BHA) and butylated hydroxytoluene (BHT), are commonly used in the pork industry, and they minimize free radical generation in pork products. In sausages, to maintain sausage quality, $0.003-0.01 \%$ BHA and BHT are added to fresh (based on fat content) or dry (based on total weight) sausages, respectively, which is allowed in the US under USDA regulations (Ahn et al., 2002; Sebra-

\footnotetext{
\#These authors contributed equally to this work.

*Corresponding author: Daekeun Shin, Department of Food and Nutrition, Hallym University, Chuncheon 200-702, Korea. Tel: 82-33-248-2132; Fax: 82-33-254-1475. E-mail address: aceflavor@hotmail.com
}

nek et al., 2005). By adding synthetic antioxidants to pork sausages, free radicals, as very reactive and unstable components, can be scavenged or chelated, thereby delaying deterioration in the flavor, color, and texture during storage (Nam and Ahn, 2003; Shin, 2006). For this reason, synthetic antioxidants are commonly used.

However, due to concerns over the safety of synthetic antioxidants by health-conscious consumers, many meat processors are now searching for alternative natural antioxidants (Shin et al., 2011), and plant extracts are generally added to pork products since many naturally derived compounds possess antioxidant and antimicrobial characteristics (Ahn et al., 2007; Sáyago-Ayerdi et al., 2009a). Grape extract contains a wide range of polyphenols and has been added to meat products in many studies. The effectiveness of grape polyphenols to retard lipid oxidation in minced fish and cooked pork and chicken has been reported (Carpenter et al., 2007; Lau and King, 2003; Sánchez-Alonso and Borderías, 2008; Sáyago-Ayerdi et al., 2009a). However, its effectiveness is limited due to the fact that the grape extract used is composed of polyphenols, which are hydrophilic. A new approach is neces- 
sary. Grape skin and seed pomace (GSP), which are generally discarded after juicing, seems to contain several flavonoids, including (+)-catechins, (-)-epicatechin, and procyanidins (Sáyago-Ayerdi et al., 2009b). It is believed that most polyphenols which remain in GSP are hydrophobic, and thus may be very effective components to stabilize free radicals in pork and pork products (Stamatis et al., 2001).

Therefore, the aim of this study was to evaluate the potential effects of GSP as a natural antioxidant and colorant in cooked pork sausages, as confirmed by TBARS and CIE L*, a*, and $\mathrm{b}^{*}$.

\section{Materials and Methods}

\section{GSP preparation}

All GSP was acquired in a local wine farm, freezedried for $2 \mathrm{~d}$ and then ground (Mini blender, Ya Hong Electronic Co., China). Ten grams of freeze-dried GSP was mixed with 100 or $75 \%$ methanol and then incubated for $24 \mathrm{~h}$ at $4^{\circ} \mathrm{C}$ (VS-8480SR, Vision Scientific Co., Korea). All incubated samples were then filtered and used for polyphenol, flavonoid, and 2,2-diphenyl-1-picrylhydrazyl (DPPH) determination, but only 20\% methanol was used as a solvent to obtain GSP extract for color determination according to $\mathrm{pH}$.

\section{GSP color determination}

All GSP incubated with $20 \%$ methanol for $24 \mathrm{~h}$ was filtered and collected, and individual GSP extracts were then read at 420, 520, and $620 \mathrm{~nm}$ using a spectrophotometer (Shimadzu 1600-UV spectrophotometer, Shimadzu Co., Japan) to calculate the color tint and yellow, red, and blue pigment percentages (Almela et al., 1995).

$$
\begin{aligned}
& \text { Color intensity }(C I)=A_{420}+A_{520}+A_{620} \\
& \text { Color tint }=\left(A_{420} / A_{520}\right) \\
& \text { Percentage of yellow }=\left[100 \times\left(A_{420} / C I\right)\right] \\
& \text { Percentage of red }=\left[100 \times\left(A_{520} / C I\right)\right] \\
& \text { Percentage of blue }=\left[100 \times\left(A_{620} / C I\right)\right]
\end{aligned}
$$

\section{Polyphenol, flavonoid, anthocyanin, and DPPH de- termination}

The total polyphenol content of GSP was measured as described by Juan and Chou (2010). Briefly, $0.1 \mathrm{~mL}$ of GSP extract and $1 \mathrm{~mL}$ of Folin-Ciocalteu reagent were mixed together and vortexed for $3 \mathrm{~min} .300 \mathrm{uL}$ of $1 \mathrm{~N}$ sodium carbonate anhydrous $\left(\mathrm{Na}_{2} \mathrm{CO}_{3}\right)$ was added, vortexed, and left at room temperature for $90 \mathrm{~min} .2 \mathrm{~mL}$ of double distilled water (DDW) was then added. The final mixture was read at $725 \mathrm{~nm}$, and the results were expressed as $\mathrm{mg} / \mathrm{mL}$ using gallic acid as a standard.

For flavonoid determination, a total of $0.5 \mathrm{~mL}$ of GSP extract and $1.5 \mathrm{~mL}$ of methanol mixture were vortexed, and $10 \%$ aluminum chloride $\left(\mathrm{AlCl}_{3}\right)$ was added. The solution was then vortexed for a further $5 \mathrm{~min}$, and $0.1 \mathrm{~mL}$ of $0.1 \mathrm{M}$ potassium acetate $\left(\mathrm{CH}_{3} \mathrm{COOK}\right)$ and $2.8 \mathrm{~mL}$ of DDW were then added and mixed. The final mixture was then read at $510 \mathrm{~nm}$ and expressed as $\mathrm{mg} / \mathrm{g}$. Quercetin was employed as a standard (Juan and Chou, 2010).

For anthocyanin determination, a modified version of the protocol described by Montes et al. (2005) was conducted. Briefly, $1 \mathrm{~g}$ of GSP was added to $100 \mathrm{~mL}$ of an ethanol and hydrochloric acid mixture (85:15), and the solution was then shaken at $4^{\circ} \mathrm{C}$ for $24 \mathrm{~h}$. Individual extracts were then filtered and read at $535 \mathrm{~nm}$, and the reading value was calculated as follows:

Anthocyanin $\mu \mathrm{g} / \mathrm{g}=[($ absorbance at $535 \mathrm{~nm} \times$ solvent volume $) /$ sample weight $] \times(1 / 65.1)$

A modification of the assay by Park et al. (2013) was performed, and $0.1 \mathrm{~mL}$ of GSP extract and $0.9 \mathrm{~mL}$ methanolic DPPH (0.1 mM) were mixed, vortexed, and left at an ambient temperature for $15 \mathrm{~min}$. The optical density of each GSP extract at $525 \mathrm{~nm}$ was read and expressed as $\mathrm{mM}$ due to the use of ascorbic acid as a standard.

\section{Cooked pork sausage preparation}

A total $14 \mathrm{~kg}$ of commercial pork loins was purchased and immediately trimmed to remove visible fat. All pork loins were then cut to an appropriate size and coarsely ground (KitchenAid Professional 600 \& KitchenAid Food Grinder Stand Mixer Attachment, KitchenAid, USA). The coarse ground pork was divided into four different groups (2.20 kg/group), including a control (CON), positive control $(0.01 \%$ sodium nitrite and $0.05 \%$ ascorbic acid, POS), $0.5 \%$ GSP $(05 \mathrm{G})$, and $1.0 \%$ GSP $(10 \mathrm{G})$ (sausage $\times$ treatment $\times$ storage day $=6 \times 4 \times 4)$. Two different concentration of GSP was pre-determined based on the results completed by Shin (2006). Pork fat and non-meat ingredients, including ice, salt, phosphate, and sugar were added and mixed (Table 1). Rough mixtures were then finely ground and blended with sodium nitrite/ascorbic acid or freeze dried GSP powder in a paddle stand mixer (KitchenAid Professional 600 \& KitchenAid Food Grinder Stand Mixer Attachment, KitchenAid, USA) for $2 \mathrm{~min}$ to achieve a uniform dissemination of each ingredient throughout the 
Table 1. Composition of pork sausage blends ${ }^{1}$

\begin{tabular}{ccccc}
\hline \hline \multirow{2}{*}{ Ingredients } & \multicolumn{5}{c}{ Pork Sausage } \\
\cline { 2 - 5 } & CON & POS & $05 \mathrm{G}$ & $10 \mathrm{G}$ \\
\cline { 2 - 5 } & & & & \\
Meat Ingredients & 73.0 & 73.0 & 73.0 & 73.0 \\
Lean pork meat & 12.0 & 12.0 & 12.0 & 12.0 \\
Pork fat & & & & \\
\hline Nonmeat ingredients & 12.76 & 12.70 & 12.26 & 11.76 \\
Ice & 0.24 & 0.24 & 0.24 & 0.24 \\
Phosphate & 1.5 & 1.5 & 1.5 & 1.5 \\
Salt & 0.5 & 0.5 & 0.5 & 0.5 \\
Sugar & - & 0.01 & - & - \\
Sodium nitrite & & & & - \\
\hline Antioxidants & - & 0.05 & - & - \\
Ascorbic acid & - & - & 0.5 & 1.0 \\
Grape skin and & -100 & 100 & 100 \\
seed pomace (GSP) & & & 100
\end{tabular}

${ }^{1}$ Treatment: $\mathrm{CON}=$ no sodium nitrite and vitamin $\mathrm{C}, \mathrm{POS}=0.01 \%$ sodium nitrite and $0.05 \%$ vitamin $\mathrm{C}, 05 \mathrm{G}=$ no sodium nitrite and $0.5 \%$ grape residual product, $10 \mathrm{G}=$ no sodium nitrite and $1.0 \%$ grape residual product.

ground pork loin matrix. The ground pork loin matrix for the control had equivalent mixing steps, but sodium nitrite, ascorbic acid, and freeze dried GSP powder were not incorporated during mixing. $10 \mathrm{~cm}$ long sausages and weighing $90 \mathrm{~g}$ were processed and cooked at $180^{\circ} \mathrm{C}$ in a convection oven (Convection FC34-1, Equipex Ltd., USA). Individual sausages were then taken out after reaching an internal temperature of $74^{\circ} \mathrm{C}$ and cooled at $4^{\circ} \mathrm{C}$ for 30 min. After cooling, two sausages were packaged together on a foam tray with a linear low-density polyethylene film (LLD-PE, Clean Sense Wrap, Cleansense, Korea) and stored in a $4^{\circ} \mathrm{C}$ refrigerator (Icepia, CLK Corporation, Korea) for $10 \mathrm{~d}$. A total of 6 sausages per treatment were used to measure $\mathrm{pH}$, objective color evaluation, thiobarbituric acid reactive substances (TBARS), and shear force on days $1,3,6$, and 10 of storage.

\section{pH and CIE $L^{*}, a^{*}$, and $b^{*}$ measurement}

For $\mathrm{pH}$ of the cooked pork sausages, a $10 \mathrm{~g}$ sausage and $90 \mathrm{~mL}$ DDW were mixed and homogenized. Duplicate readings per sample were obtained using a $\mathrm{pH}$ meter (Orion $420 \mathrm{~A}+$, Thermo Electron Co., USA). The average value of readings was reported, and the $\mathrm{pH}$ meter was calibrated with standard buffers at $\mathrm{pH} 4.0$ and 10.0 on a daily basis.

To determine the objective color space values of the pork loin sausages, each sample sausage was cut into $2 \mathrm{~cm} \mathrm{sec-}$ tions and bloomed for $10 \mathrm{~min}$. Individual CIE L* (lightness), $\mathrm{a}^{*}$ (redness), and $\mathrm{b}^{*}$ (yellowness) color space values were then determined using a colorimeter (Minolta Chro- ma Meter CR-300, Minolta Co., Ltd., Ramsey, NJ), which was calibrated daily with a white tile ( $\mathrm{Y}=94.3, \mathrm{x}=0.3130$ and $\mathrm{y}=0.3199$ ). Two different readings were taken per sample, and the average of CIE L*, $a^{*}$, and $b^{*}$ was reported.

\section{TBARS and shear force determination}

The amount of malondealdehyde (MDA) was established using a procedure described by Buege and Aust (1978). Briefly, $5 \mathrm{~g}$ of sausage, $15 \mathrm{~mL}$ of DDW, and 0.1 $\mathrm{mL}$ of BHA/BHT were homogenized and then placed in a dark room for $15 \mathrm{~min}$. Only $1 \mathrm{~mL}$ of homogenate per sample was mixed together with $2 \mathrm{~mL}$ of a TCA and TBA mixture, and boiling was conducted for $15 \mathrm{~min}$. All samples were then cooled and centrifuged. The supernatant was read, calculated, and expressed as mg malonaldehyde/ $\mathrm{kg}$ of cooked pork sausage.

TBARS $=$ Abs $530 \mathrm{~nm} \times 7.8$ (conversion factor) $\mathrm{mg}$ malonaldehyde/kg pork sausage

To evaluate the shear force of the cooked pork sausages, pork sausages were formed into $1.5 \times 1.5 \times 1.5 \mathrm{~cm}^{3}$ shapes and tempered at room temperature for $30 \mathrm{~min}$. Individually shaped samples were then cut once using an Instron 3343 (US/MX50, A\&D Co., USA) fitted with a Warner Bratzler shearing device, which generates a crosshead speed of $100 \mathrm{~mm} / \mathrm{min}$. At least fifteen different shear force values per treatment were collected, and the average value determined for each treatment was reported as $\mathrm{kg} /$ $\mathrm{cm}^{2}$.

\section{Statistical analysis}

Statistical analysis was performed using SAS software (Version 6.12, Cary, NC, USA, 1998), and a significant difference was observed by Analysis of Variance (ANOVA) using GLM procedure, followed by Duncan's Multiple Range Test with a predetermined significance level of $p<$ 0.05 .

\section{Results and Discussion}

\section{Color of GSP by pH}

To evaluate the GSP color at $\mathrm{pH} 5$ to 7 , freeze dried GSP powder was dissolved in $20 \%$ methanol, and the color tint, yellowness, redness, and blueness of GSP were determined, as described in Table 2. The GSP color tint was gradually increased, showing lighter color tint of GSP at pH $7(p<0.05)$. The results are similar to those of Bakker 
Table 2. Effect of $\mathrm{pH}$ values from $\mathrm{pH} 5$ to $\mathrm{pH} 7$ on color of grape residual product powder dissolved in $20 \%$ methanol

\begin{tabular}{|c|c|c|c|c|c|c|c|}
\hline & \multicolumn{5}{|c|}{ Grape Residual Product } & \multirow{3}{*}{ SEM } & \multirow{3}{*}{$p$-value } \\
\hline & \multicolumn{5}{|c|}{$\mathrm{pH}$} & & \\
\hline & 5 & 5.5 & 6 & 6.5 & 7 & & \\
\hline \multicolumn{8}{|l|}{ Color (\%) } \\
\hline Color Tint & $1.26^{\mathrm{c}}$ & $1.27^{\mathrm{bc}}$ & $1.29^{\mathrm{bc}}$ & $1.31^{\mathrm{b}}$ & $1.35^{\mathrm{a}}$ & 0.01 & 0.01 \\
\hline Yellowness & $41.28^{\mathrm{c}}$ & $41.56^{\mathrm{bc}}$ & $41.93^{\mathrm{bc}}$ & $42.22^{\mathrm{b}}$ & $42.90^{\mathrm{a}}$ & 0.23 & 0.01 \\
\hline Redness & $32.83^{\mathrm{a}}$ & $32.63^{\mathrm{ab}}$ & $32.45^{\mathrm{ab}}$ & $32.20^{\mathrm{bc}}$ & $31.81^{\mathrm{c}}$ & 0.14 & 0.01 \\
\hline Blueness & $25.89^{\mathrm{a}}$ & $25.81^{\mathrm{ab}}$ & $25.62^{\mathrm{b}}$ & $25.57^{\mathrm{b}}$ & $25.29^{\mathrm{c}}$ & 0.30 & 0.01 \\
\hline
\end{tabular}

${ }^{\mathrm{a}-\mathrm{c}}$ Mean values within a row followed by the same letter are not significantly different $(p>0.05)$.

and Timberlake (1997), which showed that malvidin 3glucoside, an anthocyanin prepared from Vitis vinifera grapes, had a progressive lighting ability at $\mathrm{pH} 1.5$ to 5.0 (Heredia et al., 1998; Shin, 2006). The malvidin 3-glucoside transforms to vitisin A through interaction with pyruvic acid (Romero and Bakker, 1999), and malvidin 3-glucoside concentration in grape may be reduced. Hence, the 3-monoglucosides with malvidin, which give a dark color in grape, may then influence the lightness of pork sausages when stored (Van Buren et al., 1974). A similar tendency was determined for the yellowness of GSP, and xanthylium-like derivatives formed by the oxidation of non-aldehyde polymers in grape may be factors influencing GSP's own yellow color (Santos-Buelga et al., 1995). In contrast to the color tint and yellowness of GSP, the redness and blueness were negatively affected by the $\mathrm{pH}$ variation and were reduced when the $\mathrm{pH}$ was increased from 5 to $7(p<0.05)$.

\section{GSP polyphenol, flavonoid, anthocyanin, and DPPH determination}

The sugar and acidity of GSP were 5.15 and 0.13 , respectively, and it was observed that GSP can influence the traditional characteristics of pork sausages when it is added as an ingredient (Table 3). The polyphenol level of GSP was high in $75 \%$ methanol extraction compared to $100 \%$ methanol extraction, but an opposite result was determined for flavonoids. A remarkably high flavonoid concentration of $0.47 \mathrm{mg} / \mathrm{g}$ was observed from $100 \%$ GSP extracts. Yin et al. (2008) postulated that the antioxidant activity of flavonoids is accomplished due to the hydroxyl groups on $\beta$-ring of flavonoids, indicating that the flavonoids are one of the major compounds scavenging reactive oxygen species (ROS) (Molina et al., 2003; Pietta, 2000). In spite of this, the level of DPPH was not in agreement with the assertions of Pietta (2000) and Yin et al. (2008), and DPPH was not significantly altered in accordance with the amount of flavonoid, whether derived from 100 or $75 \%$ methanol solvents.
Table 3. Determination of polyphenol, flavonoid and anthocyanin in grape residual product powder sampled by 100 or $75 \%$ methanol

\begin{tabular}{|c|c|c|c|c|c|}
\hline & Grape & esidual & roduct & \multirow{3}{*}{ SEM } & \multirow{3}{*}{$p$-value } \\
\hline & \multicolumn{2}{|c|}{ Methanol (\%) } & & & \\
\hline & 100 & 75 & & & \\
\hline Sugar content & - & - & 5.15 & 1.33 & - \\
\hline Acidity & - & - & 0.13 & 0.01 & - \\
\hline Polyphenol (mg/g) & $2.15^{\mathrm{b}}$ & $2.25^{\mathrm{a}}$ & - & 0.02 & 0.01 \\
\hline Flavonoid (mg/g) & $0.47^{\mathrm{a}}$ & $0.34^{\mathrm{b}}$ & - & 0.02 & 0.01 \\
\hline Anthocyanin (ug/g) & - & - & 0.28 & 0.01 & - \\
\hline DPPH (mM) & 0.11 & 0.11 & - & 0.01 & 0.45 \\
\hline
\end{tabular}

$\overline{\mathrm{a}, \mathrm{b}}$ Mean values within a row followed by the same letter are not significantly different $(p>0.05)$.

\section{GSP effects on pH and CIE $L^{*}, a^{*}$, and $b^{*}$ of cooked pork sausage}

The $\mathrm{pH}$ of cooked pork sausages was not altered for up to $6 \mathrm{~d}$, but all $\mathrm{pH}$ values were elevated to the range of 6.12 to 6.19 on day 10 of storage based on the pHs of day 3 of storage (Table 4). Individual $\mathrm{pH}$ values of pork sausages were higher in the order of $\mathrm{CON}>\mathrm{POS}>05 \mathrm{G}>$ $10 \mathrm{G}$ on day 3 of storage, but the order was CON $>05 \mathrm{G}$ $>\mathrm{POS}=10 \mathrm{G}$ on day 6 of storage. Their $\mathrm{pH}$ values were significantly different from one another on both occasions $(p<0.05)$. All color space values of cooked pork sausages were affected due to the addition of sodium nitrite and GSP. Compared to the control sausages on day 10 of storage, the lightness of $05 \mathrm{G}$ and $10 \mathrm{G}$ sausages were reduced. It seems that the lightness of GSP sausage was influenced by both the amount of 3-monoglucosides contained in GSP (Van Buren et al., 1974) and the scavenging abilities of polyphenols, which breakdown heme pigments during storage (Ruberto et al., 2007; Sánchez-Alonso et al., 2008; Sánchez-Alonso and Javier Borderías, 2008). Therefore, it was concluded that CIE $\mathrm{L}^{*}$ depends on the dose of GSP addition, and significantly lower CIE L* values were determined in $10 \mathrm{G}$ sausages than those determined in $05 \mathrm{G}$ sausages. A similar tendency was observed in $\mathrm{CIE} \mathrm{a}^{*}$ of $05 \mathrm{G}$ and $10 \mathrm{G}$ sausages. GSP sausages showed 
Table 4. Effect of grape residual product powder addition on $\mathrm{pH}$ and $\mathrm{CIE} \mathrm{L}^{*}, \mathrm{a}^{*}$, and $\mathrm{b}^{*}$ of cooked pork sausages stored at $4^{\circ} \mathrm{C}$ for 10 days

\begin{tabular}{|c|c|c|c|c|c|c|}
\hline \multirow{2}{*}{ Storage day } & \multicolumn{4}{|c|}{ Pork Sausage } & \multirow{2}{*}{ SEM } & \multirow{2}{*}{$p$-value } \\
\hline & $\mathrm{CON}$ & POS & $05 \mathrm{G}$ & $10 \mathrm{G}$ & & \\
\hline \multicolumn{7}{|l|}{$\mathrm{pH}$} \\
\hline 1 & 6.27 & 6.26 & 6.26 & 6.26 & 0.01 & 0.98 \\
\hline 3 & $6.11^{\mathrm{a}}$ & $6.02^{\mathrm{b}}$ & $5.94^{\mathrm{bc}}$ & $5.90^{\mathrm{c}}$ & 0.02 & 0.01 \\
\hline 6 & 6.05 & 6.01 & 6.02 & 6.00 & 0.01 & 0.21 \\
\hline 10 & $6.19^{\mathrm{a}}$ & $6.13^{c}$ & $6.15^{\mathrm{b}}$ & $6.12^{\mathrm{c}}$ & 0.01 & 0.01 \\
\hline \multicolumn{7}{|l|}{ Lightness (CIE L*) } \\
\hline 1 & $75.27^{\mathrm{a}}$ & $74.21^{\mathrm{b}}$ & $73.41^{\mathrm{bc}}$ & $72.99^{c}$ & 0.23 & 0.01 \\
\hline 3 & $76.10^{\mathrm{a}}$ & $75.13^{\mathrm{a}}$ & $74.15^{\mathrm{b}}$ & $72.28^{\mathrm{c}}$ & 0.33 & 0.01 \\
\hline 6 & $76.44^{\mathrm{a}}$ & $75.03^{b}$ & $74.01^{\mathrm{c}}$ & $72.66^{\mathrm{d}}$ & 0.32 & 0.01 \\
\hline 10 & $75.28^{\mathrm{a}}$ & $74.68^{\mathrm{a}}$ & $73.43^{\mathrm{b}}$ & $72.21^{\mathrm{c}}$ & 0.28 & 0.01 \\
\hline \multicolumn{7}{|l|}{ Redness (CIE a*) } \\
\hline 1 & $0.92^{\mathrm{d}}$ & $6.64^{\mathrm{a}}$ & $1.60^{\mathrm{b}}$ & $1.22^{\mathrm{c}}$ & 0.49 & 0.01 \\
\hline 3 & $0.90^{\mathrm{c}}$ & $6.39^{\mathrm{a}}$ & $1.47^{\mathrm{b}}$ & $1.17^{\mathrm{bc}}$ & 0.48 & 0.01 \\
\hline 6 & $1.37^{\mathrm{b}}$ & $6.22^{\mathrm{a}}$ & $1.28^{\mathrm{b}}$ & $1.23^{\mathrm{b}}$ & 0.45 & 0.01 \\
\hline 10 & $1.37^{\mathrm{b}}$ & $6.12^{\mathrm{a}}$ & $1.28^{\mathrm{b}}$ & $1.22^{\mathrm{b}}$ & 0.44 & 0.01 \\
\hline \multicolumn{7}{|l|}{ Yellowness (CIE b*) } \\
\hline 1 & $13.20^{\mathrm{a}}$ & $9.41^{\mathrm{c}}$ & $12.55^{\mathrm{b}}$ & $12.50^{\mathrm{b}}$ & 0.32 & 0.01 \\
\hline 3 & $12.81^{\mathrm{a}}$ & $9.12^{\mathrm{b}}$ & $12.79^{\mathrm{a}}$ & $12.34^{\mathrm{a}}$ & 0.33 & 0.01 \\
\hline 6 & $13.02^{\mathrm{a}}$ & $8.79^{\mathrm{b}}$ & $12.55^{\mathrm{a}}$ & $12.51^{\mathrm{a}}$ & 0.36 & 0.01 \\
\hline 10 & $13.38^{\mathrm{a}}$ & $8.79^{b}$ & $12.52^{\mathrm{b}}$ & $12.60^{\mathrm{b}}$ & 0.39 & 0.01 \\
\hline
\end{tabular}

${ }^{1}$ Treatment: $\mathrm{CON}=$ no sodium nitrite and vitamin $\mathrm{C}, \mathrm{POS}=0.01 \%$ sodium nitrite and $0.05 \%$ vitamin $\mathrm{C}, 05 \mathrm{G}=$ no sodium nitrite and $0.5 \%$ grape residual product, $10 \mathrm{G}=$ no sodium nitrite and $1.0 \%$ grape residual product.

${ }^{\mathrm{a}-\mathrm{c}}$ Mean values within a row followed by the same letter are not significantly different $(p>0.05)$.

Table 5. Effect of grape residual product powder addition on TBARS and shear force of cooked pork sausages stored at $4^{\circ} \mathrm{C}$ for 10 days

\begin{tabular}{|c|c|c|c|c|c|c|}
\hline \multirow{2}{*}{ Storage day } & \multicolumn{4}{|c|}{ "Pork Sausage } & \multirow{2}{*}{ SEM } & \multirow{2}{*}{$p$-value } \\
\hline & $\mathrm{CON}$ & POS & $05 \mathrm{G}$ & $10 \mathrm{G}$ & & \\
\hline \multicolumn{7}{|l|}{ TBARS (mg MDA/kg) } \\
\hline 1 & $1.12^{\mathrm{a}}$ & $0.54^{\mathrm{d}}$ & $0.71^{\mathrm{c}}$ & $0.89^{\mathrm{b}}$ & 0.05 & 0.01 \\
\hline 3 & $1.49^{\mathrm{a}}$ & $0.63^{\mathrm{d}}$ & $0.78^{\mathrm{c}}$ & $0.93^{\mathrm{b}}$ & 0.07 & 0.01 \\
\hline 6 & $1.50^{\mathrm{a}}$ & $0.69^{\mathrm{d}}$ & $0.91^{\mathrm{c}}$ & $1.12^{\mathrm{b}}$ & 0.06 & 0.01 \\
\hline 10 & $1.81^{\mathrm{a}}$ & $0.76^{\mathrm{d}}$ & $0.96^{\mathrm{c}}$ & $1.30^{\mathrm{b}}$ & 0.09 & 0.01 \\
\hline \multicolumn{7}{|l|}{ Shear force $\left(\mathrm{g} / \mathrm{cm}^{2}\right)$} \\
\hline 1 & 0.61 & 0.79 & 0.79 & 0.71 & 0.03 & 0.06 \\
\hline 3 & 0.59 & 0.74 & 0.77 & 0.73 & 0.03 & 0.06 \\
\hline 6 & $0.58^{\mathrm{b}}$ & $0.73^{\mathrm{a}}$ & $0.68^{\mathrm{a}}$ & $0.78^{\mathrm{a}}$ & 0.02 & 0.01 \\
\hline 10 & $0.63^{b}$ & $0.78^{\mathrm{a}}$ & $0.81^{\mathrm{a}}$ & $0.81^{\mathrm{a}}$ & 0.02 & 0.01 \\
\hline
\end{tabular}

${ }^{1}$ Treatment: $\mathrm{CON}=$ no sodium nitrite and vitamin $\mathrm{C}, \mathrm{POS}=0.01 \%$ sodium nitrite and $0.05 \%$ vitamin $\mathrm{C}, 05 \mathrm{G}=$ no sodium nitrite and $0.5 \%$ grape residual product, $10 \mathrm{G}=$ no sodium nitrite and $1.0 \%$ grape residual product.

${ }^{\mathrm{a}-\mathrm{d}}$ Mean values within a row followed by the same letter are not significantly different $(p>0.05)$.

reduced CIE a* values compared to POS sausages, which is thought to be due to the anthocyanin present in grape skin (Boulton, 2001; Kobayashi et al., 2004) being removed with the grape juice (Rababah et al., 2008), resulting in the majority of bioactive compounds remaining in GSP being fat soluble. One fat-soluble bioactive compound of GSP is carotenoid, which generates a yellow color in grape skin (Mendes-Pinto et al., 2005; Mortensen, 2006). In line with this, a significant decrease in CIE $\mathrm{a}^{*}$ values and a contrasting increase in CIE b* values of $05 \mathrm{G}$ and $10 \mathrm{G}$ cooked pork sausages tended to be observed after storage up to 6 day compared to those of POS sausages.

\section{GSP effects on TBARS and shear force of cooked pork sausage}

The scavenging properties of GSP were proven, as evidenced by TBARS in Table 5. The addition of GSP to cooked pork sausages seems to prolong the quality over 
time when $0.5 \%$ GSP was added to raw pork sausages which were then cooked. Such results were continuously maintained for up to $10 \mathrm{~d}$ of storage, but TBARS of $0.5 \%$ GSP sausages was not lower than sausages containing $0.05 \%$ ascorbic acid and $0.01 \%$ sodium nitrite. TBARS of $10 \mathrm{G}$ sausages was higher than that of $05 \mathrm{G}$ sausages. Similar TBARS was noticed by Sáyago-Ayerdi et al. (2009a) in raw chicken hamburgers, but not in cooked ones. According to their study, 1.0\% grape antioxidant dietary fiber (GADF) addition was more effective to prolong the shelf life of both raw and cooked chicken hamburgers than $2.0 \%$ GADF for up to $13 \mathrm{~d}$ of storage. Either salt or GSP ingredients, as described in Table 1, releases iron of the heme protein of pork (Sáyago-Ayerdi et al., 2009 b) or contains ferric and ferrous ions (Danilewicz, 2003), thereby accelerating lipid oxidation. The catalysis of pork sausage lipid oxidation also seems to be hastened due to the interactions of pro-oxidant flavonoids (Aguirrezábal et al., 2000; Dangles et al., 2000; Joubert et al., 2005; Procházková et al., 2011), but this interaction must be minor because of limited storage. Therefore, the addition of $1.0 \%$ GSP to pork sausages can generate more lipid oxidation than might be expected. However, structural breakdown due to lipid oxidation did not affect shear force values. No significantly different shear forces were determined for up to $3 \mathrm{~d}$ of storage $(p>0.05)$, but after that, a difference was established among control and treatment groups only $(p<0.05)$.

\section{Conclusions}

The GSP color was influenced and seemed to have effects on polyphenol and flavonoid contents due to the variation of $\mathrm{pH}$ and methanol solvent, respectively. The addition of $0.5 \%$ GSP in pork sausages retards lipid oxidation, but $1 \%$ GSP did not effectively scavenge ROS formation due to the confirmation of TBARS. Therefore, due to concerns regarding the safety and toxicity of BHA and BHT in pork meat-based foods, $0.5 \%$ GSP could prompt antioxidant activities in the cooked pork sausages.

\section{Acknowledgements}

This research was completed with financial support from both the basic science research program through the National Research Foundation of Korea (NRF) funded by the Ministry of Education (\#2012R1A1A2007394), and Chonbuk National University (2012), for which we are deeply appreciative.

\section{References}

1. Agirrezábal, M. M., Mateo, J., Dominguez, M. C., and Zumalacárregui, J. M. (2000). The effect of paprika, garlic and salt on rancidity in dry sausages. Meat Sci. 54, 77-81.

2. Ahn, J., Gruen, I. U., and Fernando, L. N. (2002). Antioxidant properties of natural plant extracts containing polyphenolic compounds in cooked ground beef. J. Food Sci. 67, 1364-1369.

3. Ahn, J., Gruen, I. U., and Mustapha, A. (2007). Effects of plant extracts on microbial growth, colour change, and lipid oxidation in cooked beef. Food Microbiol. 24, 7-14.

4. Almela, L., Javaloy, S., Fernandez-Lopez, J. A., and LopezRoca, J. M. (1995). Comparison between the tristimulus measurements Yxy and $L^{*} a^{*} b^{*}$ to evaluate the colour of young red wines. Food Chem. 53, 321-327.

5. Angelo, A. J. St. (1996). Lipid oxidation in foods. Crit. Rev. Food Sci. 36, 175-224.

6. Bakker, J. and Timberlake, C. F. (1997). Isolation, identification, and characterization of new color-stable anthocyanins occurring in some red wines. J. Agric. Food Chem. 45, 35-43.

7. Boulton, R. (2001). The copigmentation of anthocyanins and its role in the color of red wine: A critical review. Am. $J$. Enol. Vitic. 52, 67-87.

8. Buege, J. and Aust, S. D. (1978). Microsomal lipid peroxidation. Method Enzymol. 52, 302-310.

9. Carpenter, R., O'Grady, M. N., O'Callaghan, Y. C., O'Brien, N. M., and Kerry, J. P. (2007). Evaluation of the antioxidant potential of grape seed and bearberry extracts in raw and cooked pork. Meat Sci. 76, 604-610.

10. Dangles, O., Dufour, C., and Fargix, G. (2000). Inhibition of lipid peroxidation by quercetin and quercetin derivatives: antioxidant and prooxidant effects. J. Chem. Soc. Perkin Trans. 2. 2, 1215-1222.

11. Danilewicz, J. C. (2003). Review of reaction mechanisms of oxygen and proposed intermediate reduction products in wine: Central role of iron and copper. Am. J. Enol. Vitic. 54, 73-85.

12. Heredia, F. J., Francia-Aricha, E. M., Rivas-Gonzalo, J. C., Vicario, I. M., and Santos-Buelga, C. (1998). Chromatic characterization of anthocyanins from red grapes-I. $\mathrm{pH}$ effect. Food Chem. 63, 491-498.

13. Joubert, E., Winterton, P., Britz, T. J., and Gelderblon, W. C. A. (2005). Antioxidant and pro-oxidant activities of aqueous extracts and crude polyphenolic fractions of rooibos (Aspalathus linearis). J. Agric. Food Chem. 53, 10260-10267.

14. Juan, M. Y. and Chou, C. C. (2010). Enhancement of antioxidant activity, total phenolic and flavonoid content of black soybeans by solid state fermentation with Bacillus subtilis BCRC 14715. Food Microbiol. 27, 586-591.

15. Kobayashi, S., Goto-Yamamoto, N., and Hirochika, H. (2004). Retrotranposon-induced mutations in grape skin color. Science 304, 982.

16. Lau, D. W. and King, A. J. (2003). Pre- and Post-mortem use of grape seed extract in dark poultry meat to inhibit development of thiobarbituric acid reactive substances. J. Agric. Food 
Chem. 51, 1602-1607.

17. Mendes-Pinto, M. M., Ferreira, A. C. S., Caris-Veyrat, C., and De Pinho, P. G. (2005). Carotenoid, chlorophyll and chlorophyll-derived compounds in grapes and port wines. J. Agric. Food Chem. 53, 10034-10041.

18. Molina, M. F., Sanchez-Reus, I., Iglesias, I., and Benedi, J. (2003). Quercetin, a flavonoid antioxidant, prevents and protects against ethanol-induced oxidative stress in mouse liver. Biol. Pharm. Bull. 26, 1398-1402.

19. Montes, C., Vicario, I. M., Raymundo, M., Fett, R., and Heredia, F. J. (2005). Application of tristimulus colorimetry to optimize the extraction of anthocyanins from Jaboticaba ( $M y$ ricia Jaboticaba Berg.). Food Res. Int. 38, 983-988.

20. Mortensen, A. (2006). Carotenoids and other pigments as natural colorants. Pure Appl. Chem. 78, 1477-1491.

21. Nam, K. C. and Ahn, D. U. (2003). Use of antioxidants to reduce lipid oxidation and off-odor volatiles of irradiated pork homogenates and patties. Meat Sci. 63, 1-8.

22. Park, J. H., Kang, S. N., Shin, D., Hur, I. C., Kim, I. S., and Jin, S. K. (2013). Antioxidant activities of Achyranthes japonica Nakai extract and its application to the pork sausages. Asian Australas. J. Anim. Sci. 26, 287-294.

23. Pietta, P. G. (2000). Flavonoids as antioxidants. J Nat. Prod. 63, 1035-1042.

24. Procházková, D., Boušová, I., and Wilhelmová, N. (2011). Antioxidant and prooxidant properties of flavonoids. Fitoterapia 82, 513-523.

25. Rababah, T. M., Ereifej, K. I., Al-Mahsneh, M. A., Ismaeal, K., Hidar, A. G., and Yang, W. (2008). Total phenolics, antioxidant activities, and anthocyanins of different grape seed cultivars grown in Jordan. Int. J. Food Prop. 11, 472-479.

26. Romero, C. and Bakker, J. (1999). Interactions between grape anthocyanins and pyruvic acid, with effect of $\mathrm{pH}$ and acid concentration on anthocyanin composition and color in model solutions. J. Agric. Food Chem. 47, 3130-3139.

27. Ruberto, G., Renda, A., Daquino, C., Amico, V., Spatafora, C., Tringali, C., and De Tommansi, N. (2007). Polyphenol constituents and antioxidant activity of grape pomace extracts from five Sicilian red grape cultivars. Food Chem. 100, 203210.

28. Sánchez-Alonso, I., Jiménez-Escrig, A., Saura-Calixto, F., and Borderías, A. J. (2008). Antioxidant protection of white grape pomace on restructured fish products during frozen storage. LWT-Food Sci. Technol. 41, 42-50.
29. Sánchez-Alonso, I. and Javier Borderías, A. J. (2008). Technological effect of red grape antioxidant dietary fibre added to minced fish muscle. Int. J. Food Sci. Technol. 43, 10091018.

30. Santos-Buelga, C., Bravo-Haro, S., and Rivas-Gonzalo, J. (1995). Interactions between catechin and malvidin 3-monoglucoside in model solutions. Z. Lebensm. Unters Forsch 201, 269-274.

31. SAS (1998). SAS User Guide to Statistics. Version 6.12. SAS Inst. Inc., Cary, NC USA.

32. Sáyago-Ayerdi, S. G., Brenes, A., and Goòi, I. (2009a). Effect of grape antioxidant dietary fiber on the lipid oxidation of raw and cooked chicken hamburgers. LWT-Food Sci. Technol. 42, 971-976.

33. Sáyago-Ayerdi, S. G., Brenes, A., Viveros, A., and Goòi, I. (2009b). Antioxidative effect of dietary grape pomace concentrate on lipid oxidation of chilled and long-term frozen stored chicken patties. Meat Sci. 83, 528-533.

34. Sebranek, J. G., Sewalt, V. J. H., Robbins, K. L., and Houser, T. A. (2005). Comparison of a natural rosemary extract and BHA/BHT for relative antioxidant effectiveness in pork sausage. Meat Sci. 69, 289-296.

35. Shin, D. (2006). Antioxidant, color and sensory properties of sorghum bran in pre-cooked ground beef patties varying in fat and iron content. M. S. thesis, Texas A\&M University, College Station, TX. USA.

36. Shin, D., Yang, H. S., Min, B. R., Narciso-Gaytán, C., Sánchez-Plata, M. X., and Ruiz-Feria, C. A. (2011). Evaluation of antioxidant effects of vitamin $\mathrm{C}$ and $\mathrm{E}$ alone and in combination with sorghum bran in a cooked and stored chicken sausage. Korean J. Food Sci. An. 31, 693-700.

37. Stamatis, H., Sereti, V., and Kolisis, F. N. (2001). Enzymatic synthesis of hydrophilic and hydrophobic derivatives of natural phenolic acids in organic media. J Mol. Catal. B: Enzym. 11, 4-6.

38. Van Buren, J. P., Hrazdina, G., and Robinson, W. B. (1974). Color of anthocyanin solution expressed in lightness and chromaticity terms. Effect of $\mathrm{pH}$ and type of anthcyanin. Food Sci. 39, 325-328.

39. Yin, J., Si, C. L., and Wang, M. H. (2008). Antioxidant activity of flavonoids and their glucosides from Sonchus oleraceus L. J Appl. Biol. Chem. 51, 57-60.

(Received 2013.8.2/Revised 2014.2.25/Accepted 2014.3.6) 